\title{
College Students' Perceptions Regarding Medical Waivers for Wellness Incentives Under the Affordable Care Act
}

\author{
Yosuke Chikamoto $^{1}$ and DaraVazin ${ }^{2}$ \\ ${ }^{1}$ Mount Sinai Health System \\ ${ }^{2}$ California State University, Fullerton
}

\begin{abstract}
Background and Purpose: The use of health-contingent financial incentives in promoting employee wellness is controversial because of potential discrimination against those who could not reach certain health goals due to health factors. To protect consumers from such discrimination, the Affordable Care Act (ACA) requests protective mechanisms; however clear and detailed guidelines for the medical waivers have yet to be developed. This study aimed to identify college students' opinions about employee wellness programs where monetary incentives are given for those whose Body Mass Index falls into the normal range with particular attention to medical waivers. Methods: A cross-sectional survey study was conducted with participants consisting of a convenience sample of 58 college students in California. Results: Some scenarios were considered more legitimate for waivers than others (pregnancy, 67.3\%; chronic back pain; 43.1\%; broken leg, 38\%; and steroid use; 34.5\%). The non-medical reason of "trying to lose weight" was also considered legitimate by $21 \%$ of respondents. Responses varied by participants' gender and their own weight status. Conclusion: College students did not view all scenarios as legitimate reasons for medical waivers. These findings call for physicians to develop a list of legitimate reasons for medical waivers, and for physician preparedness in discussing these issues with patients.
\end{abstract}

(O2016Californian Journal of Health Promotion. All rights reserved.

Keywords: incentives, medical waivers, behavior change, obesity, worksite wellness

\section{Introduction and Purpose}

The Affordable Care Act (ACA), enacted in 2010, is the healthcare reform established in order to increase accessibility and affordability to health services for all Americans, including college students. This reform provides regulations for worksite health programs to assure that positive outcomes could be achieved by these programs. Furthermore, the employees and, in some cases, their dependents, would be protected from unfair practices in the design and implementation of the programs (Chan Osilla, Van Busum, Schnyer, WozarLarkin, Eibner, \&Mattke, 2012). The regulations include relatively detailed guidance about the use of financial incentives. However, no official guidelines on medical waivers were found under ACA or in consensus statements from professional associations such as the American College of Occupational and Environmental
Medicine, the American Cancer Society, the Cancer Action Network, the American Diabetes Association, and the American Heart Association (The Health Enhancement Research Organization, 2012).

An increasing number of employers are offering worksite health programs with the anticipation of positive outcomes such as healthy behavior change, health risk reduction, disease management, healthcare cost reduction, and improved productivity (Pinkstaff, 2014). One of the common challenges that worksite health programs face is low participation that would limit their impact. To increase participation, the use of financial incentives has been introduced (Buck Consultants, 2010). In early stages of incentive wellness programs, action-based incentives were provided for those who voluntarily participated in certain programs such as a health risk assessment, biometric 
screenings, and smoking cessation classes. More recently, outcome-based incentives have been introduced, in which the attainment of outcomes such as normal-range Body Mass Index (BMI), blood pressure, and cholesterol readings, are incentivized (The Health Enhancement Research Organization, 2012). Such outcomes can be influenced by one's current health/disease status, which may make it harder, if not impossible, to achieve health outcome goals.

One strategy designed to avoid discrimination based on one's current health status, in compliance with American Disabilities Act (ADA), is to rely on primary care physicians to decide whether the incentivized health outcomes goals are reasonably achievable for individuals with specific health conditions. If such individuals receive medical waivers from their physicians, they could become eligible for financial incentives or for alternative ways to receive the incentives (US Department of Treasury, 2014). Without clear examples in guidelines for medical waivers as a reference, physicians may encounter difficult conversations with patients who request medical waivers. This type of clinical encounter could place a burden on the physician and threaten the physicianpatient relationship. This would not be in alignment with the intended goals of worksite health programs or ACA (Pomernz, 2014).

Little is known about the general public's perceptions, specifically those of current and future consumers, of what constitutes legitimate medical waivers. College students represent current and future generation of consumers of health care products and services. For this reason, the use of a college student sample seemed particularly appropriate and timely.

The purpose of this study was to identify college-aged students' opinions about medical waivers for employee wellness programs where monetary incentives are given for those whose
Body Mass Index falls in the normal range. We also examined whether these findings varied by participant gender and BMI status (overweight or obese).

\section{Methods}

\section{Participants}

The cross-sectional study consisted of undergraduate college students at a California university. Approximately 200 students in two Health Science courses were approached to participate in the survey, of which 58 students (29\%) fully completed the survey. Of the sample, $79 \%$ were female, $21 \%$ were male; the mean age of students was 22.5 years. The sample represented the gender of students declared as a Health Science major.

\section{Measures}

Respondents were asked to read a hypothetical letter (See Figure 1) from the HR department of a company that described an outcome-based wellness incentive plan in which employees with a BMI of less than 25 would be eligible to receive $\$ 100$ a month (within the allowable incentive amount under the ACA). The letter then explains that the employee is ineligible to receive the incentive due a BMI higher than the criteria range. Respondents were then asked to read and rate their opinions about whether medical doctors should sign waivers for each of nine scenarios (Table 1) when presented by their patients. A5-point Likert-type scale was used, ranging from "the medical doctor should definitely sign a waiver," to "... definitely should not." The initial list of common reasons for medical waivers and scenarios was established by two wellness professionals with doctoral degrees, based on their experiences with wellness coaching and clinical encounters. Two physicians were then asked to review the initial list and add any reasons that they could foresee or delete reasons that would probably never come up. 
Table 1:

Percentage of the Respondents Who Reported That Physicians Should "Definitely" or "Probably" Sign a Waiver ( $\mathrm{n}=53$ ).

\begin{tabular}{lcc}
\hline \multicolumn{1}{c}{ Reasons } & $\mathrm{N}$ & \multicolumn{1}{c}{$\%$} \\
\hline 1. "I am pregnant. That's why I am heavier than usual." & 39 & 67.3 \\
2. "I have a chronic back pain, which prevents me from exercising." & 25 \\
3. "Last year I broke my leg on the job. It's a workers' comp case. I gained weight because I & 22 \\
haven't been able to exercise as much." & 20 \\
4. "I take steroids to control my asthma. It's because of the side effect of the steroids why I & 38.1 \\
cannot control my weight." & 13 \\
5. "I have been trying to exercise and eat right for 3 years. And I have been losing weight. But & 34.5 \\
my BMI is not quite at the recommended level yet." & 3 \\
6. "Both my parents and all my siblings are obese. My weight is hereditary." & 22.8 \\
7. "I have been paying a lot out-of-pocket for my son's medical treatment. I could definitely & \\
use the \$100 incentive money." & 2 \\
8. "Last year I quit smoking. That's why I gained weight." & 2 \\
9. "I just do not enjoy exercising." & 3.1 \\
\hline
\end{tabular}

Figure 1:

The Hypothetical Letter from the Human Resources Department

Dear employees,

To encourage health and wellness among our employees, we are providing $\$ 100$ cash incentive per month for those whose Body

Mass Index (BMI) is below 25. BMI is commonly used to evaluate whether someone is within an ideal healthy weight (below 25),

overweight (between 25 and 30) or obese (30 or above). A BMI table is provided below for your reference.

According to the results from the biometric screening event last month, your Body Mass Index (BMI) was above the

recommended healthy value of 25 . We encourage that you lose weight and become eligible for this $\$ 100 /$ month incentive next

year.

If your medical condition makes it "unreasonably difficult" to attain the goal of achieving BMI of less than 25 or if the goal is

“medically inadvisable" for you, please ask your doctor to sign a medical waiver form.

If you submit a signed medical waiver form to us, you will be eligible for the $\$ 100 /$ month incentives this year.

Sincerely,

Human Resources Department

The addition of steroid use as a reason for making it unreasonably difficult to achieve the desired BMI was the only change that the physicians made to the original list. Demographic information included gender, age, height, weight, and self-reported health on a scale ranging from poor to excellent.

\section{Procedures}

The instructors made announcements in their classes and sent emails that explained the purpose of the study, along with a link to access the online survey. The Institutional Review Board of the second author's affiliation reviewed and approved the use of human subjects for this study.

\section{Analyses}

Descriptive statistics were calculated for all variables of interest. A Wilcoxon signed rank test was run to compare participants' selected responses across the nine scenarios. Lastly, Chisquare analyses were run to determine whether there were gender differences and BMI status 
differences on their responses to the nine different scenarios. All analyses were conducted using SPSS.

\section{Results}

A total of 58 undergraduate college students at a public university in California participated in this study. The mean age of the students was $22.5(\mathrm{SD}=6.1)$ and $79.3 \%$ were female. Slightly over half $(51.7 \%)$ reported good health, $36.3 \%$ reported fair health, and $12.1 \%$ reported excellent health. Percentages of respondents' perceptions regarding whether doctors should sign a medical waiver for various reasons are presented in Table 1.

A Wilcoxon rank test was run and the results were significant $(\mathrm{p}=.000)$, indicating that not all reasons for medical waivers were considered equally legitimate by respondents. Table 1 demonstrated that pregnancy was the highest rated legitimate reason for a medical waiver, followed by having chronic back pain, breaking a leg on the job, and use of steroids for asthma management. The lesser ranked scenarios were not enjoying exercising, weight gained because they quit smoking, and weight being hereditary. Although these scenarios were not highly ranked, some respondents still included them as reasons for which a physician should "definitely" or "probably" sign a medical waiver.

There were significant gender and weight status differences in the perceived legitimacy of the scenarios. Chi-square results presented in Table 2 indicated that females were far more likely to view back pain as a legitimate reason for a waiver $(52.2 \%)$ compared to males $(9.1 \%)$. Furthermore, overweight/obese participants were more likely to agree that a lack of exercise due to weight being hereditary was a legitimate reason for a waiver (13.4\%) compared to their normal weight counterparts $(2.4 \%)$. Males $(11.1 \%)$ and overweight/obese participants $(15.4 \%)$ were more likely to agree that a lack of exercise due to smoking cessation was a legitimate reason for a waiver compared to females $(2.2 \%)$ and normal weight individuals $(0 \%)$. Overweight participants were more likely to agree with scenario 7 , "I have been paying a lot out-of-pocket for my son's medical treatment. I could definitely use the $\$ 100$ incentive money" $(6.7 \%)$, compared to normal weight participants $(2.4 \%)$. All of these results had a p-value of <.05.

Table 2:

Gender and Weight Status Differences in Responses to Scenarios Who Reported Physicians Should "Definitely" or "Probably"

\begin{tabular}{|c|c|c|c|c|c|}
\hline \multicolumn{6}{|c|}{ Sign a Waiver } \\
\hline & & $\begin{array}{l}\text { Male } \\
(n=11)\end{array}$ & $\begin{array}{l}\text { Female } \\
(n=46)\end{array}$ & $\begin{array}{l}\text { Overweight/ } \\
\text { Obese } \\
(n=15)\end{array}$ & $\begin{array}{l}\text { Normal Weight } \\
(\mathrm{n}=41)\end{array}$ \\
\hline 1. & Scenario1(pregnancy) & $9(81.9 \%)$ & $30(65.2 \%)$ & $7(46.6 \%)$ & $31(75.7 \%)$ \\
\hline & Scenario $2^{\text {a }}$ (back pain $)$ & $1(9.1 \%)$ & $24(52.2 \%)$ & $3(20.0 \%)$ & $22(53.7 \%)$ \\
\hline & Scenario3 (broken leg) & $4(36.4 \%)$ & $17(36.9 \%)$ & $4(26.7 \%)$ & $17(41.5 \%)$ \\
\hline & Scenario4(steroids) & $5(45.5 \%)$ & $14(30.4 \%)$ & $6(40.0 \%)$ & $14(34.2 \%)$ \\
\hline & Scenario5 3 year effort) & $2(18.2 \%)$ & $12(24.5 \%)$ & $4(26.7 \%)$ & $9(22.5 \%)$ \\
\hline 6. & Scenario6 ${ }^{\mathrm{b}}$ (family obese) & $1(9.1 \%)$ & $2(4.4 \%)$ & $2(13.4 \%)$ & $1(2.4 \%)$ \\
\hline 7. & $\begin{array}{l}\text { Scenario } 7^{c} \text { (pay out of pocket, use the } \\
\text { money) }\end{array}$ & $2(18.2 \%)$ & $1(0.0 \%)$ & $1(6.7 \%)$ & $1(2.4 \%)$ \\
\hline 8. & Scenario8 ${ }^{c}$ quit smoking) & $1(11.1 \%)$ & $1(2.2 \%)$ & $2(15.4 \%)$ & $0(0.0 \%)$ \\
\hline 9. & Scenario $9^{c}$ (do not enjoy exercise) & $1(10.0 \%)$ & $1(2.2 \%)$ & $2(15.4 \%)$ & $0(0.0 \%)$ \\
\hline
\end{tabular}

${ }^{a}$-Significant gender difference $(\mathrm{p}<.05)$

${ }^{\mathrm{b}}$ Significant weight status difference $(\mathrm{p}<.05)$

${ }^{c}$ Significant gender and weight difference $(p<.05)$ 


\section{Discussion}

The results of this study are considered a preliminary step in understanding the nature of consumer decision-making represented by college students in the area of medical incentives. One of the major findings was differing opinions among the sample in terms of what should be considered legitimate reasons for medical waivers in wellness programs that use outcome-based incentives. There is a general tendency to agree upon the legitimacy of medically-oriented reasons represented by pregnancy, chronic back pain, a broken leg, and use of steroids for asthma management. The non-medical reason of a 3-year effort to lose sufficient weight to result in BMI under 25was not rated high; approximately one in five people thought that the doctor should sign a medical waiver.

In regard to the demographic differences, responses to scenarios varied by gender and weight status. The rate of endorsement with a certain scenario might have to do with their (college students') relationship with the scenario. For example, people who are obese are more likely to have back pain. A study on the interrelationship between low back pain and obesity identified increased BMI as a risk factor for back pain (Smuck, Kao, Brar, Martinez-Ith, \&Tomkins-Lane, 2014). It may also indicate that overweight/obese undergraduate students might have a slight tendency to feel justified to ask for a waiver under these circumstances. One study on motivational factors to achieve and maintain healthy weight in college students found normal weight students had greater affective motivation, self-efficacy, and intrinsic motivation compared to overweight students (Furia, Lee, Strother,Huang, 2009). These findings could be an indication of which types of waivers by gender and body weight males and females are more likely to ask for.

In the absence of a medical consensus or guidelines in the medical community, it is left up to each physician to decide which reasons are legitimate. These findings suggest two potential issues: difficult clinician-patient conversations and the potential for perceived unfairness. When patients request medical waivers based on reasons that their physicians do not consider legitimate, the physicians would have to refuse the requests by helping the patients understand why the reasons were not proper, which could not only increase time for clinical encounters but also possibly compromise trusting doctor-patient relationships. This pilot study suggests that physicians need to be prepared to have potentially difficult conversations about the medical waivers. These findings call for a more concerted effort between the medical community and wellness service providers in establishing and explaining a clear standard of medical guidelines for waivers.

\section{Limitations}

The following limitations should be considered when interpreting the study findings: in general, the sample was relatively small; responses of "probably" and "definitely" were limited for 3 out of the 9 scenarios presented. The study consisted of a convenience sample of college students, which could limit the generalizability of the results to older populations and those with children. The survey asked the respondents' thoughts about whether the doctor should or should not sign a waiver, instead of the employee's actual action, or even behavior intention, of requesting a waiver. Thus, the hypothetical reasons might not seem as real to the respondents, which might not have elicited the proxy of their likely actions if they actually had those reasons for themselves. A study with a larger sample size and a variety of questions regarding each scenario is worth further exploration.

\section{Conclusion}

College students did not view all scenarios as equally legitimate reasons for medical waivers. Females were more likely to view back pain as a legitimate reason for a waiver (52.2\%) compared to males $(9.1 \%)$. These findings provide some indication about which types of waivers might be more commonly requested, by gender and weight status. With this information in hand, physicians can take a more concerted effort to establish a priority list of legitimate reasons to consider medical waivers, and to be more 
prepared to discuss medical waiver issues with their patients. Further research is warranted to examine the opinions of other segments of the population in more detail, particularly working adult consumers, who are more likely to receive this type of financial incentive arrangement.

\section{Acknowledgement}

We would like to thank Hoang Kim Trinh,BS, formerly an undergraduate student at University of California, Berkeley, for his contributions to this study.

\title{
References
}

Bibbins-Domingo, K., Burroughs-Pena, M., (2010). Caring for the "young invincibles." Journal of General Internal Medicine25 (7), 642.doi:10.1007/s11606-010-1388-8

Buck Consultants.Working Well: A Global Survey of Health Promotion and Worksite Wellness Strategies.San Francisco, CA: Buck Consultants; 2010.

Chan Osilla, K., Van Busum, K., Schnyer, C., Wozar Larkin, J., Eibner, C., \&Mattke, S. (2012). Systematic Review of the Impact of Worksite Wellness Programs. American Journal of Managed Care, 18(2), 368-381.

Furia, A., Lee, R., Strother, M., Huang, T., (2009). College students' motivation to achieve and maintain a healthy weight. American Journal of Health Behavior. 33(3), 256-263.

Michaels, C., \& Greene, A. (2013). Worksite wellness: Increasing adoption of workplace health promotion programs. Health Promotion Practice, 14(4), 473-479.

Pinkstaff, S. (2014). The Affordable Care Act: new opportunities for cardiac rehabilitation in the workplace? Journal of Occupational and EnvironmentalMedicine.56(8), 809-813.

Pomeranz, J. (2014). Workplace wellness programs: how regulatory flexibility might undermine success. American Journal of Public Health, 104(11), 2052-2056.

Smuck, M., Kao, M., Brar, N., Martinez-Ith, A., Choi, J., Tomkins-Lane, C. (2014). Does physical activity influence the relationship between low back pain and obesity? The Spine Journal, 14(2), 209-216.

The Health Enhancement Research Organization, American College of Occupational and Environmental Medicine, American Cancer Society and American Cancer Society Cancer Action Network, American Diabetes Association, American Heart Association. (2012). Guidance for a reasonably designed, employer-sponsored wellness program using outcomes-based incentives: a joint consensus statement. Journal of Occupational and Environmental Medicine, 54, 889-896.

US Department of the Treasury, Department of Labor, Department of Health and Human Services.Incentives for Nondiscriminatory Wellness Programs in Group Health Plans; Final Rules. Available at: http://www.gpo.gov/fdsys/pkg/FR-2013-06-03/pdf/2013-12916.pdf. Accessed February 4, 2014.

\author{
Author Information \\ DaraVazin, EdD, MPH, CHES \\ Department of Health Science \\ California State University, Fullerton \\ 800 N. State College Blvd. \\ Fullerton, CA 92831-3599 \\ 657-278-3435 (office) \\ dvazin@fullerton.edu \\ * corresponding author
}

